InOedia $\quad \begin{aligned} & \text { InMedia } \\ & \text { The French Journal of Media Studies }\end{aligned}$

8.1. $\mid 2020$

Ubiquitous Visuality

\title{
Dealing with Long Duration: TV Series, Aesthetics and Close Analysis
}

Ariane Hudelet

\section{(2) OpenEdition \\ 12 Journals}

\section{Electronic version}

URL: http://journals.openedition.org/inmedia/1931

DOI: 10.4000/inmedia.1931

ISSN: 2259-4728

\section{Publisher}

Center for Research on the English-Speaking World (CREW)

\section{Electronic reference}

Ariane Hudelet, "Dealing with Long Duration: TV Series, Aesthetics and Close Analysis", InMedia [Online], 8.1. | 2020, Online since 15 December 2020, connection on 26 January 2021. URL: http:// journals.openedition.org/inmedia/1931 ; DOI: https://doi.org/10.4000/inmedia.1931

This text was automatically generated on 26 January 2021.

(C) InMedia 


\title{
Dealing with Long Duration: TV Series, Aesthetics and Close Analysis
}

\author{
Ariane Hudelet
}

1 Contemporary visual experiences seem to be mostly characterized by their brief and fragmented nature - the multiplication of screens and their extreme portability, as well as the development of transmedia, have enhanced the fragmentation phenomenon, corresponding to what Nicholas Mirzoeff calls "the disjunctured and fragmented culture that we call postmodernism," which to him is "best imagined and understood visually, just as the nineteenth century was classically represented in the newspaper and the novel." But whereas the post-modern visual regime is overwhelmingly associated with short attention spans, ${ }^{2}$ one of today's dominant audiovisual forms is on the contrary singled out by its long duration and expansive nature-that of the TV series. Although series are also marked by a form of disruption because of their episodic character, their main feature however, is their very long duration, and their ability to engage viewers for many hours-sometimes over several months and, hopefully, over many years. ${ }^{3}$

2 Not only do viewers devote substantial portions of their lives to these fictions and become emotionally and intellectually involved with their increasingly complex narratives and characters, but they have also been engaging more actively with the audiovisual aesthetics of these series. Since the turn of the new millennium, the size and HD quality of screens have led many TV series to develop sophisticated, dense modes of visual expression by increasing the new spectatorial control over the rhythm and modes of reception and the shift to digital production and post-production technologies. Consequently, many series have come to be considered audio-visual cuvres as well as complex narratives, at the same time that they are products of the cultural industry. This has led to a paradigm shift and to new debates in terms of the academic study of these objects. Television serials approach to aesthetics has undergone a revival, after having sometimes been considered by television studies as both dated and ideologically dubious. In the past few years, scholars have increasingly defended the usefulness of careful, sustained analysis of brief passages, to gain insight 
into the shows' aesthetics, in the tradition of close reading as established notably by New Criticism, although this remains controversial, as we shall see.

3 The emergence of aesthetic analysis and close reading ${ }^{4}$ have sometimes been associated with the phenomenon of legitimation and artification ${ }^{5}$ of the form and been considered an elitist attempt to distinguish some programs from others, to establish a restrictive and prescriptive canon or aesthetic norm, against other programs such as soap operas, which have been traditionally linked with a more feminine audience, or with a lower form of cultural capital. ${ }^{6}$ But this article will suggest that detractors of aesthetic analysis and close reading tend to focus on what they consider to have been the drawbacks of such an approach in the past, rather than consider what it could bring to a new approach of long, episodic audiovisual narratives. In order for aesthetic study to be substantial and precise, it needs to tackle the texture of the shows, their form, in a microscopic way, even when this is eventually inscribed in a macroscopic perspective. This use of moments, details, fragments, is not self-evident and needs to be addressedwhat can the very short reveal about the very long, how do these brief forms, which lend themselves to close analysis, manage to shed light on the entire work? Our modes of serial literacy cannot be uniform and homogenous, but I will suggest that close reading has its place within it, based on a methodology that goes beyond usual conceptions of a clear separation between depth and surface.

\section{The aesthetics issue}

4 As Jonathan Gray and Amanda Lotz explain, TV studies emerged simultaneously with a radical shift in academia, with the advent of cultural studies and semiotics, which considered aesthetic analysis as a means rather than an end:

This revolution of semiotics and theory transformed how many within the humanities made sense of their role as professors and analysts. If the Arnoldian project of teaching and understanding beauty had once been dominant, it was now rivalled by a concern for how texts created our identities and the world around us, and hence for how texts could serve as the site where identities and the world could be changed. Television studies would be born in and from this moment in which it became vital to inquire into a text's ideological role. Formal analysis would still prove important, but television studies tended to engage in formal analysis primarily as a means to the end of determining any given show's place within a network of power. ${ }^{7}$

5 Consequently, aesthetic analysis has sometimes been considered as a suspicious practice, a phenomenon that is linked with the fact that, as Jason Jacobs and Steven Peacock in their introduction to Television Aesthetics and Style point out, "academic work on television remains, for the most part, entrenched in theoretical frameworks." Sarah Cardwell, in her article included in the same volume, offers a detailed history and analysis of this bias against aesthetics in the field of TV studies, showing how aesthetics is felt to be "reactionary, harking back to old methods and values that have no place in the study of a popular, mass medium."

6 TV series have undergone a process of "artification" since the end of the 20th century, starting with what Thompson calls the "second Golden Age" in the $1980 \mathrm{~s},{ }^{10}$ quickly followed by a third golden age, sometimes called "quality television," 11 or "complex TV, usually associated with the turn of the $21^{\text {st }}$ century and series such as The Sopranos, Six Feet Under or The Wire." 12 This new "artistic" status of some television shows has often 
been associated with audiovisual sophistication (sometimes qualified as "cinematic," a contentious term), with narrative complexity associated with multiple and intricate narrative arcs and serialized instead of episodic storylines, as well as with renewed interest for the processes of creation and for strong authorial figures. ${ }^{13}$ This process has led some series to be seen in a new light and to be considered as part of a culture that extends from highbrow to lowbrow. This phenomenon, however, has been considered as problematic by many media and TV specialists. As Karen Lury summarizes in her introduction to the issue of Screen entitled "Situating Television Studies":

On the one hand these high-end dramas are rich texts, garnering critical acclaim and a loyal following. They inspire and, perhaps, can bear the weight of, a mode of critical analysis that serves to [...] provide analysis that is on a par with the best critical writing on cinema and literature. [...] In opposition to this, other scholars are dismayed by what they perceive to be an increasing focus on a narrow range of texts that apparently privilege a particular mode of television programming and a specific audience demographic. In addition, an on-going concern is that a focus on these programmes-and what some have seen as an indulgent or exclusively stylistic analysis that engages with these texts-too easily ignores important issues of taste and gender as well the (local) economies of television production and consumption. ${ }^{14}$

7 For the most adamant critics indeed, focusing on form and aesthetics can be regressive and can even constitute "a pre-structuralist danger." 15

While these critiques bring up relevant issues related to cultural legitimation and the sociological classification of culture, they also tend to focus on past forms of aesthetic reading rather than consider what an open, comprehensive aesthetic analysis could bring to current objects. Sarah Cardwell reminds us that, while aesthetics as a philosophical concept "has historically been concerned with difficult questions regarding definitions of art; the nature of our engagement with art; questions of taste; and the interrogation of art in terms of beauty, truth and value(s)," aesthetic analysis however has also "addressed ontological, moral and psychological questions," in addition to the common "logical, conceptual and epistemological" concerns. ${ }^{16}$ Focusing on aesthetics does not signify political or ideological blindness and aesthetics can be seen as a tool rather than an end, an approach that does not disregard the close connection between the serial form and the logic of the capitalist market economy, ${ }^{17}$ but acknowledges the fact that the primarily commercial purpose of these cultural products does not annihilate any aesthetic import they might have. ${ }^{18}$

9 Several scholars have called for a rejuvenation of the aesthetic approach to television series in the past decade, a process that would logically follow the "resurgence of stylistic criticism" in film studies about which Jacobs and Peacock have written. ${ }^{19}$ These scholars calling for better integration of aesthetics into TV studies, of course, do not recommend "fetishized analysis for its own sake," ${ }^{20}$ but rather consider that close attention to form would sustain and enrich all forms of critical analysis.

10 By re-centering analytical focus on the role and impact of form, recent TV criticism and academic study have contributed to showing how the density and complexity of the audiovisual form of TV series deserve to be considered fully and in detail in order to sustain all types of analytical and critical reflections. For instance, Jason Mittell's notion of "forensic fandom" explains that the new manifestations of "complex TV," based on intricate, multiple story arcs and serialized plot, "create magnets for engagement, drawing viewers into story worlds and urging them to drill down to 
discover more." ${ }^{21}$ For Mittell, complex TV encourages a "vertical descent into a text's complexities," but this should not eclipse other forms of cultural engagement:

Privileging depth over breadth is a knee-jerk response bred in the humanities, where complexity is a marker of quality over surface pleasures of sensation and surprise that are more typical in spreadable media. However, we need to shift our normative stance to allow that both spreadable attractions and drillable complexity are legitimate forms of cultural engagement, differently appropriate depending on a viewer's context and goals. ${ }^{22}$

11 A focus on aesthetics can thus allow us to consider the heterogeneities, paradoxes, irregularities that also characterize such expansive forms as TV series, moments that can only be grasped in the full consideration of their surface as well as their depth.

\section{Close reading: reinvesting the surface}

12 The late arrival of close analysis to television shows (there was practically none before the 1970s) ${ }^{23}$ can be first, and quite logically, explained by the ephemeral nature of television programs before the 1980s. It was then indeed virtually impossible to watch a TV program again, unless it was a re-run, and one had no way of stopping the flow of television, of controlling its rhythm, of pausing or isolating specific passages-practices that are crucial for close analysis. The arrival of VHS, then DVDs, and later streaming and VOD, would change all this in the following decades.

Another real problem that we, as scholars working on TV series, experience, is the pedestrian but important point that Gray and Lotz make: "formal analysis takes a lot of time," ${ }^{24}$ and thus it is difficult to imagine it could be implemented globally. The idea of selection then becomes crucial, and something we also encounter when teaching TV series: to what extent can we expect our students to know the material in its entirety? What degree of scrutiny do we expect from them with regard to the entire series? Wouldn't close reading necessarily monopolize their attention and thus prevent them from focusing on whole pieces of work, on the bigger picture, or on more relevant issues? ${ }^{25}$

14 I would suggest here that, just as a restriction of focus is necessary for scientific analysis to be possible, there cannot be a universal mode of handling an entire series, because of the problems of long duration as well as narrative and aesthetic complexity. These long works are difficult to handle, both materially (we need to juggle between several DVDs, or digital files) and mentally (how can our brains retain the detail of such long, evolving, fluid works?). ${ }^{26}$ Just as scientific inquiry requires the choice of adequate tools (whether scalpel, knife or saw, microscope or telescope), scholars who study television series have to select the right optical frame according to their approach and goal: should we strive for a comprehensive vision of such massive works, and is such a thing even possible? Or should we rely on fragments, and if so, which ones? While the process of selecting such moments is manageable when dealing with a traditional 90 to 120-minute feature film, it becomes a whole different matter when the entire work is 60 - or 120 -, or 300 -hours long. ${ }^{27}$ The long duration of the series leads, in many instances, to variations of tone and quality, rhythm and themes that sometimes border on disruption or incoherence. The method we thus use to understand and make sense of them needs to be fluid in order not to erase or ignore these variations and irregularities. Focusing on details, fragments, moments, allows us to be more attentive 
to the phenomenological dimension of television viewing. It acknowledges the surface of the series and tries to account for its expressiveness and complexity.

Whether or not to analyse "details" has been a common concern of hermeneutics, critical analysis, and history. When studying literature, music, or painting, can we build interpretations from only one or even several details? Can we draw conclusions on an entire novel from a one-page passage? Can we isolate a single detail from a painting and draw a potentially deviant interpretation from it? French art historian Daniel Arasse defended this approach by making "the detail" the lens through which he proposes to analyse works of art. For him, the detail constitutes a heuristic "divergence" from, and "resistance" to the entire painting. He defends critics who choose to "stick their noses up to the canvas" and "graze the painting," a way of looking which reveals a feeling of "intimacy, be it that of the painting, of the painter, or of the very act of painting." 28 of course a detail from a series is necessarily different from the detail in a painting-the term can apply to different things: a photogram, a sound that by essence cannot be still, or a shot, scene or sequence. But in spite of the complexity brought by movement and time, this isolation of a small portion of a larger entity does call for a similar attitude on the part of the spectators. We are encouraged, not so much to move closer to the screen (even though it is increasingly close, with more viewing of TV series taking place on computer screens, tablets or smartphones, rather than TV screens), but to sharpen and slow down our mode of looking, or to engage in re-viewings, in order to be alert to the way series trigger our emotions beyond the narrative immersion that is most commonly considered their defining power. ${ }^{29}$

16 Close aesthetic analyses of the series can allow us to give full status to emotions, to the connection between the work and the viewers. Without pretending to speak for a single, abstract type of viewership, we of course need to take into account the diversity of individually situated responses. The intense, combined intellectual and emotional engagement of TV viewers is one of the basic, defining features of serial narratives. ${ }^{30} \mathrm{In}$ order to understand the process of emotion stimulation, we need to resort to aesthetics in the simple sense mentioned by Sudeep Dasgupta, that of a "sensory experience produced in an encounter." ${ }^{31}$ Close analysis manages to enhance what he calls "nonresolvable opacities" in TV series, that is to say, moments which constitute breaks within the televisual text, and which "absorb viewers into the sensory power of the presence of images while pulling them out of the narrative's investigatory dynamic." A mixed method is thus, necessary to account for "the hybrid experiential encounter with the television serial," between "absorption and expulsion" (theatrical presentation, narrative absorption and visual involvement), which produces "an oscillation between deciphering meaning and registering presence." ${ }^{32}$ This is nothing radically new, since similar reflections have been applied to film as well-for instance Tom Gunning has studied the spectacular effects of blockbusters as the persistence of "the cinema of attractions" of the early years of cinema, in which specific moments of "attraction" suspended or interrupted the narrative flow, outside of any linear narrative progression. ${ }^{33}$ Thomas Elsaesser summarizes these binary oppositions that can be used to structure the history of cinema as "spectacle/narrative," "numbers principle/linear action," "interaction with the audience/passive reception" - pairings that can also provide an effective typology for the aesthetics of TV series today. ${ }^{34}$ 


\section{Which moments and why?}

17 As James Walters and Tom Brown point out in the introduction to Film Moments, a moment "is not a fixed measurement," 35 and meanings will vary and remain subjective. It can focus on a single element of the frame-an object, choice of color or composition, an actress's gesture, a voice inflection, a specific sound texture, the choice of a cut or dissolve, or of a specific camera angle. It can be the combination of elements in a scene that can last for a second or several minutes. It can be a recurring feature that matters precisely because of its recurring nature. The selection of details, fragments or moments logically derives from internal and external factors: organically as it were, the episodic form of the series itself isolates some special moments-cold open, title sequence, cliff-hanger, for instance-that naturally lend themselves to closer analysis. But the main perspectives driving the analysis will also logically direct the type of fragments that will be selected. Finally, selection is also a collective, collaborative process, for we are increasingly likely to come across specific moments that have been selected by others, for instance on YouTube or social media. As Mittell points out, TV shows cannot be considered as "bounded, clearly defined, stable objects of study" but are "suffused within and constituted by an intertextual web that pushes textual boundaries outward, blurring the experiential borders between watching a program and engaging with its paratexts. ${ }^{36}$ Considering which moments emerge, and why, is thus also a way to interrogate the interaction between series and audience, modes of consumption and reception, and audience engagement.

We therefore need to question the strategies by which our attention or emotions are triggered in some moments rather than others. In a world in which our attention is constantly caught by a diversity of images and sounds, the coherence and duration offered by the serial world offers some sense of continuity, thanks to the familiarity that is built along dozens, even hundreds, of episodes. The simple process of noting what moments or details "percolate" on the first viewing or after several subsequent viewings, as early as the pilot episode, or after hours spent in intimacy with the characters and their environment, is meaningful.

The typical moments that could be seen as particularly fruitful for the close analysis of series are the thresholds that characterize the interruptions, repetitions, and renewals, all of which are essential to the serial form. Opening credits sequences have recently attracted stimulating academic focus, after being long overlooked as purely functional or informative. ${ }^{37}$ Attention has also been brought to the endings of episodes, and of series themselves, with the increasing departure both from the open-endedness of seriality, since serial narratives have traditionally been less teleologically driven than films. ${ }^{38}$ But models of closure have started to be associated with specific series in the past decades, ${ }^{39}$ and the strong ending of Friends, Seinfeld, The Sopranos, The Wire, Six Feet Under, or Breaking Bad, have led to passionate reactions by fans and substantial academic focus.

20 A type of scene can also be used to serve as an analytical framework, allowing the theorisation of an aesthetic mode of knowledge. This has been the case for crime board scenes in which pictures, bits of papers, newspaper clippings, sometimes objects, are connected visually on a vertical board thus lending themselves to the inquisitive, analytical look of a detective, a murderer, or a journalist. This object and the scenes built around it become for Rob Coley "an epistemic tool" associated with "narrative 
deceleration," and contribute to "the theorisation of an aesthetic mode of knowledge." ${ }^{40}$ Among the abundance of images and visual experiences that the audience is confronted with, pin-boarding allows us to build a sense of truth as the plot develops. In Anne Ganzert's recent doctoral thesis, pin-boarding is taken as main analytical framework, a way of synthesizing, simplifying, or visually combining different elements, which reminds us also of the boards used in writers' rooms in Hollywood. She argues that pin-boarding allows series to make their own apparatus visible for the viewers in the long tradition of diagrams and diagrammatic art. ${ }^{41}$

Finally, a myriad of details in the form of objects, gestures, looks, costumes, voice inflection, natural or technological sounds, or types of silences, are increasingly the object of television analysis. Mad Men for example stands out in its use of objects and period detail, which has sometimes been described as bordering on fetishism. ${ }^{42}$ Whereas style used to be mostly associated with specific genres in the first decades of television, many series today have a "signature style" (including, for example, offbalanced framings in Mr Robot, or shallow focus in The Handmaid's Tale) that goes beyond genre or period, and that encourages viewers and critics to pay attention to cinematography and sound design notably. ${ }^{43}$ of course, high-end dramas do not have a monopoly over "style" - all types of programs, from sitcoms to soap operas, from procedural dramas to highly serialized shows, can lend themselves to fruitful, minute analysis. As has been extensively studied by Jeremy Butler, soap operas notably were the first to be stylistically analysed by specialists of melodrama, in spite of their being associated with "zero-degree style" because of their production constraints. ${ }^{44}$ But highend dramas such as Game of Thrones, which will be the object of my case study, offer striking examples of moments that combine audiovisual complexity and sophistication and that shed light on the percolation process in the digital media landscape.

Let us, then develop one moment among the innumerable ones that could lend themselves to close analysis, a passage which will mostly illustrate the increasing seduction and impact of moments of "attractions" in recent series, as well as the collective process that leads to abundant discourse of specific moments. It seems fitting to pick Game of Thrones, a series that has been praised for its production values and spectacular aesthetics, ${ }^{45}$ as it embodies the new horizons opened up for television by digital technology and cultural legitimacy.

The episode entitled "Battle of the Bastards" 46 particularly fed viewers' desire to dissect and analyse, notably because its creators and producers clearly aimed to "offer the viewer a pleasure that is not normally available on television: the pleasure of gazing, of considering the image as image." 47 It notably features a 30-minute sequence of a pitched-field battle that marks an important moment in the plot, when one of the most unbearable characters, Ramsay Bolton, is to be defeated, beaten to a pulp, and finally eaten by his own dogs. But more than just serving the progression of the plot, the sequence aims at immersing the viewers in a visceral, sensory experience of battle, thus, positioning itself in line as one of the most spectacular battles in the history of screen narratives. By then, after 6 seasons, viewers had also come to expect that kind of lavish display from this show, for which this type of spectacle had become a trademark. Yet, this sequence stood out within the system of the show for several reasons, including of course its production value, since the shooting took 55 days, against an average of 6 to 8 days for an episode generally, and boasted a \$10M dollar budget. The long duration and the progressive structure of the sequence also allowed it to develop 
specific visual and aural motifs-for instance line vs. circle, order vs. chaos, martial cacophony vs. elegiac music-that contribute to balancing a general view of military strategy and an organic perception of the horrors of battle.

Although the sequence serves a strong narrative purpose since this is a turning point in the story, notably in the balance of power between Sansa, Jon and Ramsay, its impact relies mostly on its virtuoso status, showcasing to what extent the series can explore its own modes of expression, notably these moments of "attractions". With almost no dialog, the passage resorts to an impressive variety of tropes and techniques, a quasicomprehensive panorama of audiovisual grammar. From the extreme-long shots and bird's eye views of the battlefield allowing us to grasp the overall logic of the troops (evoking similar shots in famous cinematic battle scenes, from Ran to Lord of the Rings), to the close-ups and telelens shots of the soldiers fighting or the horses galloping, followed by fluid tracking or steadicam shots, our vision alternates between distance and immersion. The sequence could also serve as a lesson in blocking and mise-enscène in film and media schools, thanks to its precise staging of the troops' movements and of the directions in which the characters are looking, that manage to encapsulate their connection or opposition with a great economy of means. Depth of field and blocking also allow simultaneous actions to unfold in front of our eyes and to reinforce the hectic dimension of the battle. Variations of rhythm manage to modulate emotions, a rhythmic quality also created by the soundtrack that alternates between loud and chaotic passages (galloping horses, yelling soldiers, clanging swords and spurting blood) to moments in which noises and sounds get muffled, giving way to elegiac or epic music. These rhythmic breaks are also allowed by the editing, with a shift from heavily edited passages made of extremely brief shots, longer shots in slow motion of the galloping horses for instance, and long takes of several seconds. Graphically, the sequence is carefully built around the opposition between linear movements or motifs (spears, arrows flying or piercing bodies, the straight movement of armies rushing towards each other), circular motifs (Ramsay's troops encircling Jon's, repeatedly portrayed in bird's eye views), also contrasting the symmetry of repetitive patterns (archers bending their bows, the red design on the wall of shields) and the chaotic mayhem of the heart of the battle. This lavish display of stylistic figures aims at triggering a deeply affective, visceral response on the part of the viewers, and to make a lasting impression in their memories, as well as demonstrating the virtuous craft of the professionals, which worked, as the episode won 7 Emmy awards that year, including for directing, editing and visual effects. ${ }^{48}$

The passage also perfectly illustrates how such moments "percolate" in the reception process. A very long sequence, it is clearly separated into discreet moments-Rickon's run to his death; Jon deciding to take on the opposing army alone; the fight between the two sides which ends in Jon's army being encircled and seemingly doomed; Jon nearly being trampled, yet, emerging from a heap of dead bodies; the final rescue by the knights of The Vale, the final chase of Ramsay into the fortification of Winterfell. Among all these, three specific moments stand out in critical discussions and fan productions ${ }^{49}$. In the first one, Jon Snow, after falling from his horse, is facing, alone, the charge of dozens of horses that seem like hundreds because of the use of a long lens and shallow focus. 


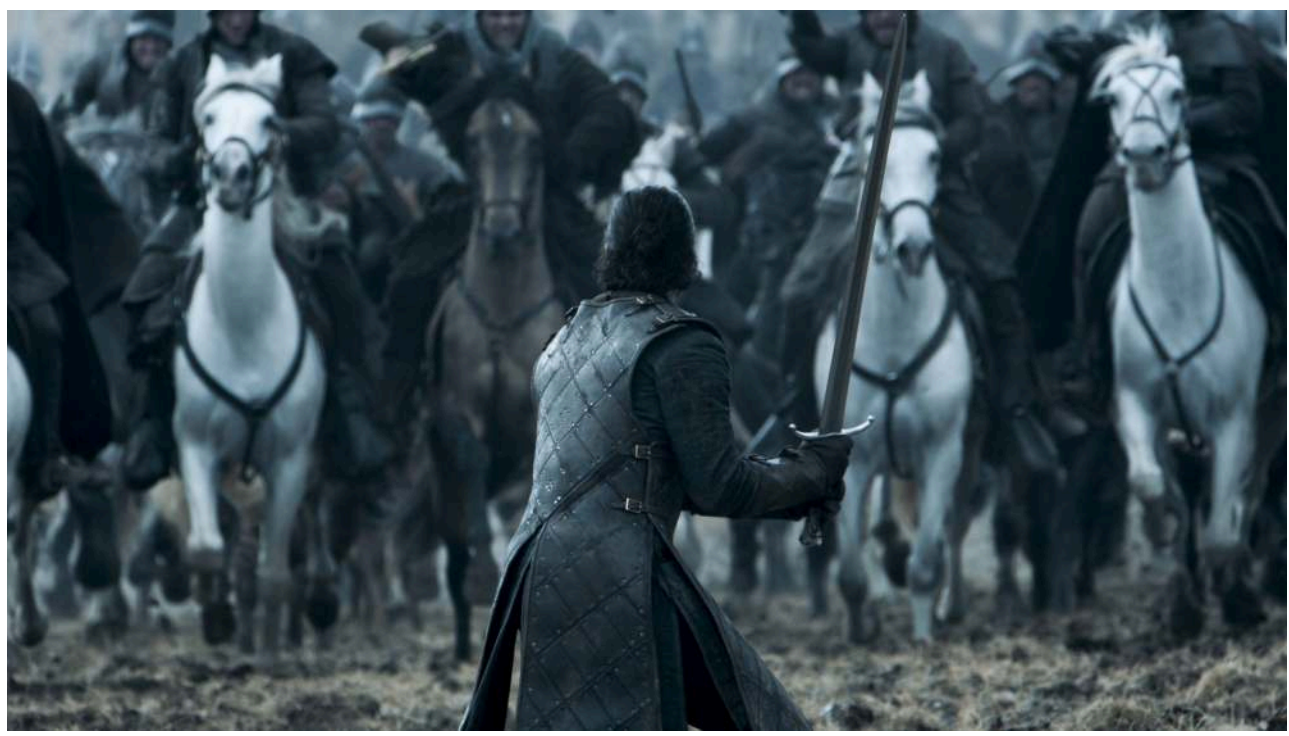

Fig. 1. Telephoto shot of Jon Snow facing the galloping horses (S06E09).

26 The second moment is a one-minute single, continuous take that shows the same Jon Snow, from up close but in a wide angle, fighting his way through the horrors of the battle, knocking enemy soldiers off their horses, striking, slashing and dodging in breathless rhythm. Soldiers and horses enter and leave the frame abruptly. The continuity of the shot is mesmerizing; the subtle choreography of fighting and mayhem manage to recreate the chaos of war, all the while keeping a clear focalization on Jon alone.

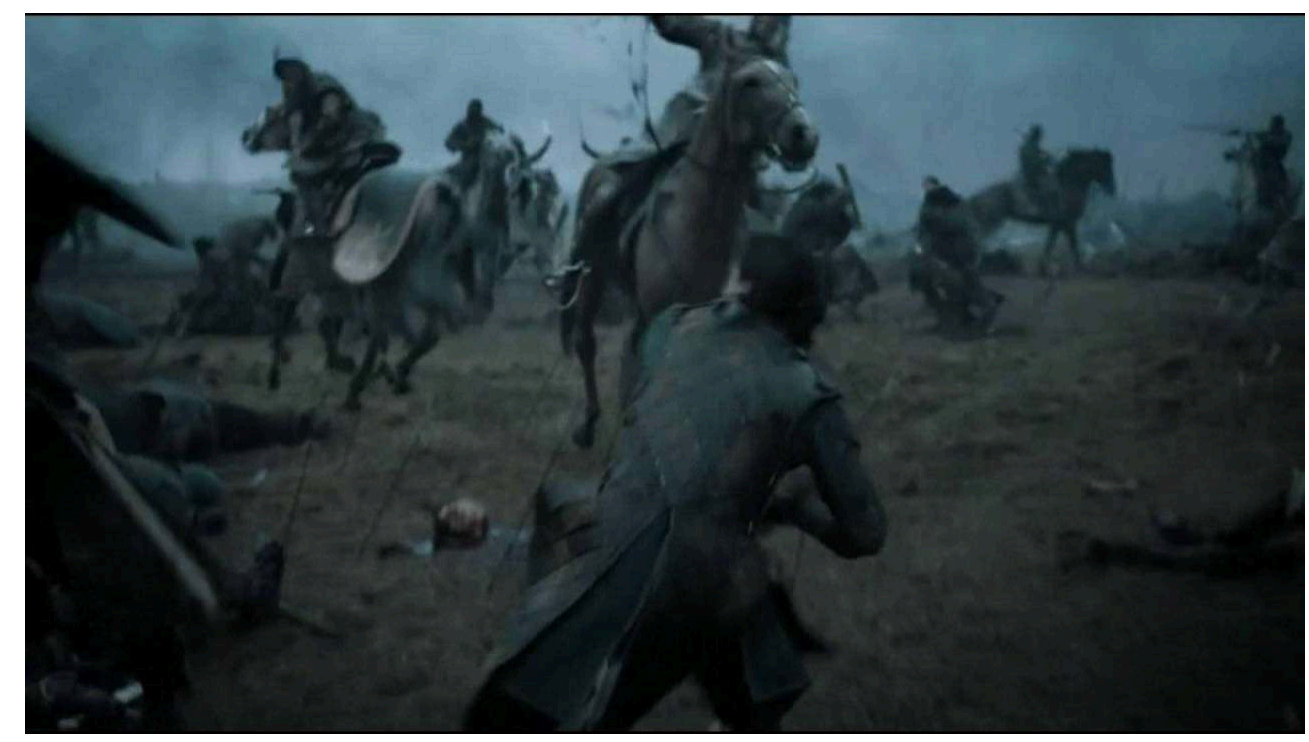

Fig. 2. Focalization remains on Jon Snow in a long, continuous take (S06E09).

The last moment shows him when he has fallen to the ground on an already impressive hill of corpses. Unable to stand up, as he is treaded upon by the fighting masses and is gradually buried under the falling bodies, his predicament is materialized on screen as viewers fully embrace his point of view: we see only dark shadows and occasional flashes of light, all sense of perspective is lost. We hear him gasp for breath, totally helpless, until he finally frees himself. 


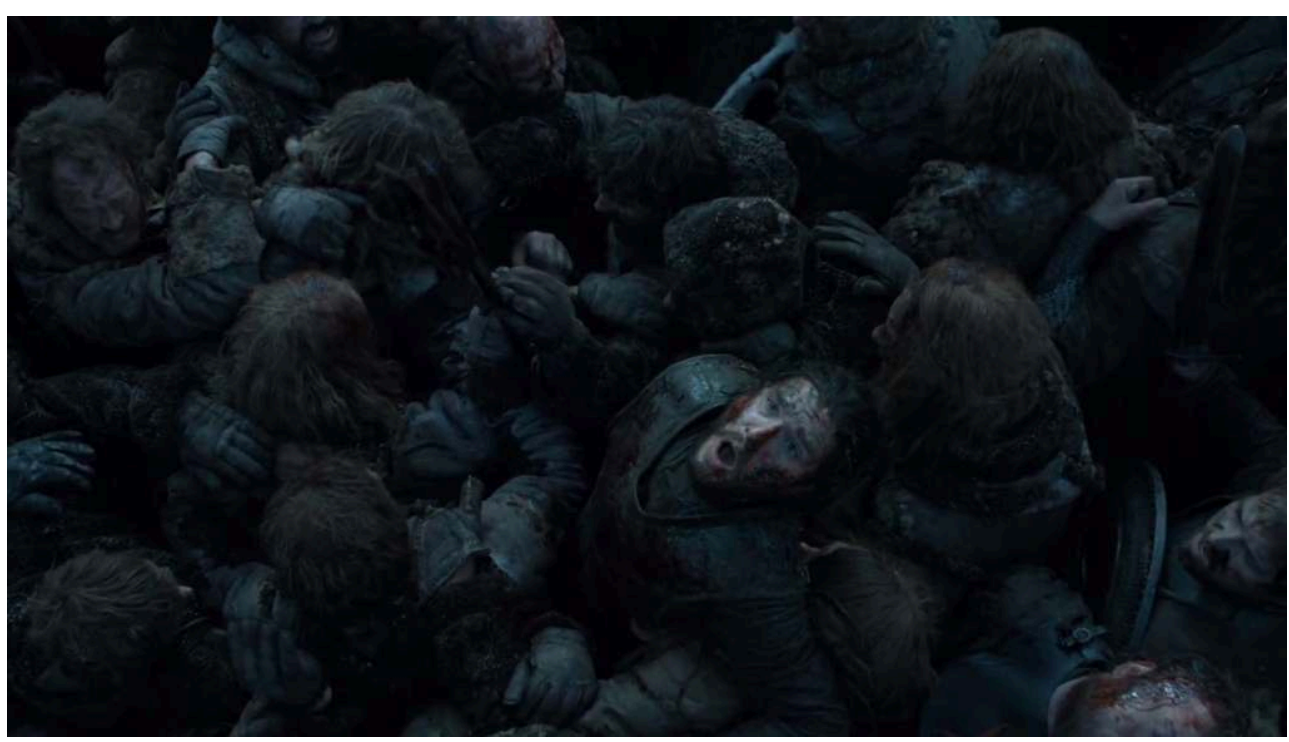

Fig. 3. Bird's eye view of Jon Snow drawing breath as he emerges from the heap of dead bodies (S06E09).

What makes these three moments stand out is the powerful sense of sensory immersion built for the audience, either thanks to the use of long lens and depth of field, or because of the continuous shot focused on Jon, or again, through the use of subjective point of view shots during the nightmarish moment in which he is almost buried alive under heaps of dead bodies. The soundtrack also contributes to the immersion, since the loud noises of sword clanking and hand-to-hand combat gradually yield to muffled battle sounds, and Jon Snow's quasi death rattle, while a slow, mournful cello melody starts. This has led the entire sequence to be compared to Spielberg's Saving Private Ryan $^{50}$, whose opening sequence also attempts to capture the soldier's individual experience of D-day as realistically as possible: one also sees and hears weapons entering organs, limbs being torn off, bodies strewn across the bloodied soil they are gradually covering. Just as the use of long focal shots, handheld or steadicam shots, and close-ups allowed us access to the soldiers' perception in Saving Private Ryan, the "Battle of the Bastards" also allows viewers to remain close to this single man who is so desperate for revenge that he recklessly throws himself into a doomed battle. However, the serial format distinguishes this spectacularly immersive passage: whereas we were discovering the characters in the overture of Spielberg's film, in Game of Thrones it comes in the $6^{\text {th }}$ season, and thus also relies on the emotional connection we feel with the characters, which has been gradually constructed over long hours of fiction prior to that scene, and which is reinforced by the recurring close-ups and exchanges of looks between the protagonists. The fact that the character we follow throughout the sequence has already returned from the dead at the beginning of the season makes his progress throughout the sequence all the more macabre, just as the series's previous depictions of violence; warfare and cruelty endow this organic exploration of the horrors of war with the value of a thematic climax.

These three moments were quickly singled out in the reception of the show. As mentioned earlier, contemporary modes of reception allow us infinite ways of observing the multiple and complex processes of selection, which emerge collectively. These three particular moments have thus instantaneously been accompanied by abundant "paratext," what Mittell calls "spreadable media" of online distribution, ${ }^{51}$ 
which also directs our viewing. ${ }^{52}$ The singling out of this particular sequence was notably orchestrated by the almost instantaneous posting on HBO's YouTube channel of a video explaining the making of the scene. "Anatomy of a Scene: The Battle of Winterfell," which quickly went viral on social media, offered ten minutes of explanation based on footage from the shooting, and interviews of the showrunners and actors enhancing the exceptional nature of the scene, stressing notably the limited role of CGI and the reliance on flesh-and-blood extras and "real horses," all of this contributing to the immersive power of the passage. ${ }^{53}$ Most of the comments, from viewers and the creative team alike, insist on the size and magnitude of the sequence, ${ }^{54}$ in short on the elements that a few years before had seemed incompatible with "the small screen," for financial and technological reasons. This seems to confirm the success of HBO's marketing and branding strategy to position themselves as providing a new form of fiction and entertainment on the small screen, as its original slogan claimed - "It's not TV. It's HBO".

The scene also bypassed the limitations of the small screen by its inclusion within the "Game of Thrones Live concert experience," an epic show that toured in North America and Europe in 2017 and 2018. Major "moments" from the show were thus projected on giant screens, accompanied by live music played by an orchestra conducted by the series" composer Ramin Djawadi on a $360^{\circ}$ stage. Rising platforms and pyrotechnics completed the immersive spectacle in which the "Battle of the Bastards" occupied a substantial place.

31 Next to this corporate enterprise of singling out specific moments within the series, ${ }^{55}$ the fans and audience themselves participate in this "percolation" phenomenon through the quick spreading of un-official mashups, re-cuts, fan-vids, supercuts, in which Internet users, fans, or more institutional YouTube channels, share their own selection, their interpretation of some scenes, or new connections they establish between different details from the series. The wave of "reaction videos," for instance, has been largely associated with Game of Thrones because of the show's tendency to rough its audience up by regularly killing some of the main characters in gruesome circumstances. Although less "shocking" in that respect than Ned Stark's death (S01E09), or the Red Wedding (S03E09), the Battle of the Bastards still figures among the top scenes for reaction videos ${ }^{56}$ which themselves attract thousands of viewers. This growing fascination for the act of watching itself testifies to the prevalence of emotions, the immediate experience of the moment, on which series like Game of Thrones, of course, heavily rely.

Besides this fascination for the way we watch and the hypnotic, potentially regressive attitude of watching ourselves/others watching, the more creative approach of vidding consists in re-cutting the original footage, adding a different music, a voiceover, or even tampering with elements of the shots or original editing. Many such examples of vidding have quickly been applied to the Battle of the Bastards, either by deciding to arm Jon Snow with a Jedi's lightsaber, ${ }^{57}$ by adding an ironic, retrospective voice-over in which Jon Snow hints at all the things he should have done differently had he given the situation just a little bit more consideration, ${ }^{58}$ or simply by adding different music, filters, or tampering with the editing. ${ }^{59} \mathrm{Jon}$ Snow unsheathing his sword and facing the galloping horses is also one of the most circulated Game of Thrones GIFs online. The very brief clip, looped, and deprived of narrative context and music, thus offers itself as a distinct aesthetic experience disconnected from its narrative context, a fragment 
detached from a larger whole subsisting essentially because of its status as "attraction." 60

Finally, the more traditional forms of criticism have also brought forward the exceptional nature of these specific moments. Video essays or magazines have very rapidly dissected the different elements of the sequence, to explain the "emotional involvement," easy to demonstrate thanks to clips from the sequence, intercut with stills, freeze frames and passages from other war films, notably to stress the major role played here by director Miguel Sapochnik, going so far as to compare him to Hitchcock. ${ }^{61}$ As far as written reviews go, in The Guardian, Sarah Hughes saw the episode as "TV's finest hour," stressing how the passage manages to make the audience "taste the reality of war." ${ }^{\prime 2}$ On the contrary, in The A.V. Club, Myles McNut considered the passage gratuitous in spite of its efficiency in providing an "adrenaline rush" for the audience. His main criticism is quite revealing: he argues that, "if we were to imagine a written version of this battle," there wouldn't be "any depth to Jon's inner monologue." Although acknowledging the passage's interest "from a technical perspective" he nevertheless considers it as a "hollow spectacle" 63 because of its lack of narrative drive. The same rhetoric of "depth" and "surface" interestingly appears here, as the main source of criticism for a passage in which audiovisual texture is devised precisely to go beyond the narrative function.

This example from Game of Thrones is deliberately extreme in its immersive, spectacular dimension, and in no way does it imply that aesthetic analysis should be limited to this type of passage only. But these specific moments of "The Battle of the Bastards" illustrate the fact that making sense of television images first requires a consideration of the multiple modes of viewing and sharing that are involved, we cannot completely separate the aesthetic impact of a passage from a reflection on modes of access; close reading evolves with the new context of a digital media ecology. In our day of mixed and transmedia, hyperlinks, and digital files, our relationship with the audiovisual text is necessarily unstable and fluctuating. With high-speed Internet, mobile media and big data, the way we implement close analysis is necessarily impacted by the selection and ways of associating these details, which also depend on technological factors.

One could suggest that the critical approach of series requires any analysis to contain similar forms of gaps and interruptions as the serial form itself, for it to be productive. By selecting fragments, basing our analysis on close reading of details or moments, we can reveal patterns, alternative understandings of expansive works that elude, because of their long duration, any all-encompassing, comprehensive grasp. Focusing on moments allows for analyses that leave room for diversity, incoherence, or paradoxes. It does allow meaning-making but can also open up the horizon for a focus on spectatorship and emotions, and the acknowledgement of potential opacities thanks to a full consideration of the surface without pre-conceived ideas of the depth it is supposed to reveal or conceal. 


\section{BIBLIOGRAPHY}

Adorno, Theodor W. and Max Horkheimer. "La production industrielle de biens culturels." In La dialectique de la raison, 129-176. Paris: Gallimard, [1944] 1969.

Arasse, Daniel. Le Détail. Paris: Champs Flammarion, 1992.

Bordwell, David. Making Meaning. Inference and Rhetoric in the Interpretation of Cinema. Cambridge [Mass.]: Harvard UP, 1991.

Butler, Jeremy. Television Style. New York and London: Routledge, 2010.

Caldwell, John Thornton. Televisuality: Style, Crisis and Authority in American Television. New Brunswick [NJ.]: Rutgers UP, 1995.

Cardwell, Sarah. "Television Aesthetics." Critical Studies in Television 1, no. 1, (Spring 2006): 72-80.

--_. "Television Aesthetics: Stylistic analysis and beyond." In Television Aesthetics and Style, edited by Jason Jacobs and Steven Peacock, 21-44. New York: Bloomsbury, 2013.

Coley, Rob. "The Case of the Speculative Detective: Aesthetic Truths and the Television "Crime Board'." NECSUS \#True, Spring 2017. https://necsus-ejms.org/the-case-of-the-speculativedetective-aesthetic-truths-and-the-television-crime-board/ <accessed on October 12, 2020> Contemporary Aesthetics. 4 "Artification", 2012. https://contempaesthetics.org/newvolume/pages/ journal.php? volume $=49$. $<$ accessed on October 12, 2020>

Dasgupta, Sudeep. "Sensing the Opaque. Seriality and the Aesthetics of Televisual Form." In Media of Serial Narrative, edited by Frank Kelleter, 183-203. Columbus: Ohio State UP, 2017.

Elsaesser, Thomas. “The New Film History as Media Archaeology.” Cinémas 14, no. 2-3, (Printemps, 2004): 75-117.

Esquenazi, Jean-Pierre. “Pouvoir des séries télévisées.” Communications 32, no. 1, (2013). https:// journals.openedition.org/communication/4931 <accessed on October 12, 2020> Feuer, Jane, Paul Kerr and Tise Vahimagi. MTM. “Quality Television.” London: BFI, 1984.

"Game of Thrones Season 6: Anatomy of A Scene: The Battle of Winterfell (HBO)." YouTube, June 19, 2016. https://www.youtube.com/watch?v=B93k4uhpf7g. <accessed on October 12, 2020>

Ganzert, Anne. “Serial Pinboarding” PhD diss., University of Konstanz, 2017.

Garcia, Alberto N., ed. Emotions in Contemporary TV Series. Basingstoke: Palgrave Macmillan, 2016.

Geraghty, Christine. "Aesthetics and Quality in Popular Television Drama." International Journal of Cultural Studies 61, no. 1, (2003): 25-45.

Gibbs John, and Douglas Pye. "Introduction." In Style and Meaning: Studies in the Detailed Analysis of Film, edited by John Gibbs and Douglas Pye. Manchester: Manchester UP, 2005.

Gray, Jonathan and Amanda Lotz. Television Studies. Cambridge: Polity, 2012.

Gunning, Tom. "The Cinema of Attraction[s]: Early Film, Its Spectator and the Avant-Garde." Wide Angle 8, no. 3-4, (1986): 63-70.

Harding, Jennifer and Deirdre Pribram, eds. Emotions: A Cultural Studies Reader. London:

Routledge, 2009. 
Hayward, Jennifer. Consuming Pleasures: Active Audiences and Serial Fictions from Dickens to Soap Opera. Lexington: University Press of Kentucky, 2009.

Heinich, Nathalie and Roberta Shapiro, eds. De l'artification. Enquêtes sur le passage à l'art. Paris: Ehess, 2012.

Heritage, Stuart. “Instant Gratification: Are Today's TV Shows Really Too Long?” The Guardian (March 1, 2018). https://www.theguardian.com/tv-and-radio/2018/mar/01/instantgratification-today-tv-shows-really-too-long. <accessed on October 12, 2020>

Hills, Matt. "Television Aesthetics: a Pre-Structuralist Danger." Journal of British cinema and Television 8, no. 1, (2011).

Hughes, Sarah. "The Battle of the Bastards: Game of Thrones Serves Up TV's Finest Hour." The Guardian (September 19, 2016). https://www.theguardian.com/tv-and-radio/shortcuts/2016/sep/ 19/battle-of-the-bastards-game-of-thrones-episode-record-seven-emmys. <accessed on October $12,2020>$

Kelleter, Frank, ed. Media of Serial Narrative. Columbus: Ohio State UP, 2017.

Jacobs, Jason and Steven Peacock, eds. Television Aesthetics and Style. New York: Bloomsbury, 2013. Klevan, Andrew. Disclosure of the Everyday: Undramatic Achievement in Narrative Film. Trowbridge: Flicks Books, 2000.

Lifschutz, Vladimir. This is the end. Finir une série télé. Tours: PUFR, 2018.

Lury, Karen. Interpreting Television. London: Hodder, 2005.

Levine, Elana and Michael Z. Newman, eds. Legitimating Television. New York: Routledge, 2012.

Logan, Elliot. “'Quality Television' as a Critical Obstacle.” Screen 57, no. 2, (Summer 2016): 144-62.

McNutt, Myles. “Thrones Stages an Epic Battle, but to What End?” The AVclub, June 19, 2016. https://tv.avclub.com/thrones-stages-an-epic-battle-but-to-what-end-expert-1798188762. $<$ accessed on October 12, 2020>

Miller, Neil. “The 140 Most Beautiful Shots of Game of Thrones." Film School Rejects (July 10, 2017). https://filmschoolrejects.com/140-beautiful-shots-game-of-thrones/. <accessed on October 12, 2020>

Mirzoeff, Nicholas. An Introduction to Visual Culture. New York and London: Routledge, 1999.

Mittell, Jason. "Narrative Complexity in Contemporary American Television", The Velvet Light Trap 58, (Fall 2006): 29-40.

- - . "Forensic Fandom and the Drillable Text." Spreadablemedia.org. http:// spreadablemedia.org/essays/mittell/ <accessed on October 12, 2020>

---. Complex TV: the Poetics of Contemporary Television Storytelling. New York: NYU Press, 2015.

Nevins, Jake. “Aesthetic Excellence: How Cinematography Transformed TV.” The Guardian, March 1, 2018. https://www.theguardian.com/tv-and-radio/2018/mar/01/tv-that-doesnt-look-like-tvhow-cinematography-relit-the-small-screen?CMP=Share_iOSApp_Other. <accessed on October $12,2020>$

Rabinowitz, Peter J., “Against Close Reading." In Pedagogy is Politics. Literary Theory and Critical Teaching, edited by Maria-Regina Kecht, 230-243. Urbana and Chicago: University of Illinois Press, 1992. 
Re, Valentina. "From Saul Bass to Participatory Culture: Opening Title Sequences in Contemporary Television Series." NECSUS (Spring 2016). https://necsus-ejms.org/saul-bassparticipatory-culture-opening-title-sequences-contemporary-tv-series <accessed on October 12 , 2020>

Rogers, Kenneth. The Attention Complex. Media, Archeology, Method. New York: Palgrave Macmillan, 2014.

Stewart, Eric. “Re-animating GIF's.” Otherzine 28, Spring 2015. http://www.othercinema.com/ otherzine/reanimating-gifs/ <accessed on October 12, 2020>

Thompson, Robert J. Television's Second Golden Age. From Hill Street Blues to ER. Syracuse: Syracuse UP, 1997.

Vérat, Eric. Génériques! Les séries américaines décryptées. Paris: Les Moutons Electriques, 2012.

Walters, James and Tom Brown, eds. Film Moments: Criticism, History, Theory. London: BFI/Palgrave Macmillan, 2010.

Zabunyan, Dork. "Des Images en séries." Art Press 2 32, "Séries télévisées. Formes, fabriques, critiques," (2014): 54-8.

Alias. Created by J.J. Abrams. ABC, 2001-2006.

American Horror Story. Created by Ryan Murphy. FX, 2011-.

Braveheart. Directed by Mel Gibson. Paramount, 1995.

Breaking Bad. Created by Vince Gilligan. AMC, 2008-2013.

Buffy the Vampire Slayer. Created by Joss Whedon. The WB, then UPN, 1997-2003.

Game of Thrones. Created by D.B. Weiss and David Benioff. HBO, 2011-2019.

Lord of the Rings (The). Directed by Peter Jackson. New Line Cinema, 2001.

Mad Men. Created by Matthew Weiner. AMC, 2007-2015.

Night Of(The). Created by Richard Price and Steven Zaillian. HBO, 2016.

Ran. Directed by Akira Kurosawa. Toho, 1985.

Saving Private Ryan. Directed by Steven Spielberg. DreamWorks, 1998.

Sopranos (The). Created by David Chase. HBO, 1999-2007.

True Detective. Created by Nic Pizzolatto. HBO, 2014-.

Wire (The). Created by David Simon. HBO, 2002-2008.

\section{NOTES}

1. Nicholas Mirzoeff, An Introduction to Visual Culture (New York and London: Routledge, 1999), 3-4.

2. For a comprehensive approach to issues related to attention, see Kenneth Rogers, The Attention Complex. Media, Archeology, Method (New York: Palgrave Macmillan, 2014).

3. The new modes of reception of these series, via DVD, streaming, downloading or VOD, have radically altered episodic logic. Whereas viewers had no choice but to wait for the next instalment when broadcast TV was the only available model, they are now free to watch their 
series when (and if) each episode is broadcast, or to consume several episodes at the same time, sometimes in a very condensed period of time-a phenomenon that has been increased by the arrival of S-VOD platforms such as Netflix, Amazon or Hulu which, most of the time, make all episodes of a single season available at the same time for their subscribers. The average number of episodes per show has also gone down since the 1950s, when the average number of episodes per season was between 26 and 39 .

4. See for instance John Thornton Caldwell, Televisuality: Style, Crisis and Authority in American Television (New Brunswick [NJ.]: Rutgers UP, 1995); Jeremy Butler, Television Style (New York and London: Routledge, 2010); Jason Jacobs and Steven Peacock, eds., Television Aesthetics and Style (New York: Bloomsbury, 2013); Sarah Cardwell, "Television Aesthetics: Stylistic Analysis and Beyond," in Television Aesthetics and Style, ed. Jacobs and Peacock (New York: Bloomsbury, 2013), 21-44; Christine Geraghty, "Aesthetics and Quality in Popular Television Drama," International Journal of Cultural Studies 61, no. 1, (2003): 25-45; Dork Zabunyan, “Des Images en séries," Art Press 2 32, (2014): 54-58.

5. I am here referring to the concept developed notably by Nathalie Heinich and Roberta Shapiro (eds.), De l'artification. Enquêtes sur le passage à l'art (Paris: EHESS, 2012). For a broad exploration of the different meanings of the term, see also Contemporary Aesthetics 4 (2012), which is devoted to "Artification."

6. For this criticism, see Elana Levine and Michael Z. Newman, eds., Legitimating Television. Media Convergence and Cultural Status (New York: Routledge, 2012).

7. Jonathan Gray and Amanda Lotz, Television Studies (Cambridge: Polity, 2012), 39.

8. Jason Jacobs and Steven Peacock, eds., Television Aesthetics and Style, 2.

9. Cardwell, "Television Aesthetics: Stylistic Analysis and Beyond," 25

10. Robert J. Thompson, Television's Second Golden Age. From Hill Street Blues to ER (Syracuse: Syracuse UP, 1997).

11. An expression popularized by Jane Feuer, Paul Kerr and Tise Vahimagi, MTM. "Quality Television" (London: BFI, 1984).

12. Jason Mittell, "Narrative Complexity in Contemporary American Television," The Velvet Light Trap 58, (Fall 2006): 29-40.

13. For instance famous showrunners such as Joss Whedon, J. J. Abrams, David Simon, Matthew Weiner and Vince Gilligan, whose popularity was during the production of, respectively: Buffy the Vampire Slayer (The WB, then UPN, 1997-2003), Alias (ABC, 2001-2006), The Wire (HBO, 2002-2008), Mad Men (AMC, 2007-2015), and Breaking Bad (AMC, 2008-2013).

14. Karen Lury, Interpreting Television (London: Hodder, 2005), 120-21.

15. In the sense of a return to a dated, subjectively hierarchical approach according to Matt Hills, "Television Aesthetics: a Pre-Structuralist Danger," Journal of British cinema and Television 8, no.1, (2011): 99-117; Levine and Newman, eds., Legitimating Television.

16. Cardwell, "Television Aesthetics: Stylistic Analysis and Beyond," 29.

17. A phenomenon studied by Jennifer Hayward in Consuming Pleasures: Active Audiences and Serial Fictions from Dickens to Soap Opera (Lexington: University Press of Kentucky, 2009).

18. Thus going against the logic deriving from the theoretical bases laid out by the Frankfurt school that explicitly compared cultural industries to totalitarian regimes; see Theodor Adorno and Max Horkheimer, "La production industrielle de biens culturels," in La dialectique de la raison (1944, Paris: Gallimard, 1969): 129-76.

19. Referring to, for instance, John Gibbs and Douglas Pye, eds., Style and Meaning: Studies in the Detailed Analysis of Film (Manchester: Manchester UP, 2005); Andrew Klevan, Disclosure of the Everyday: Undramatic Achievement in Narrative Film (Trowbridge: Flicks Books, 2000); James Walters and Tom Brown, eds., Film Moments: Criticism, History, Theory (London: BFI/Palgrave Macmillan, 2010).

20. Gray and Lotz, Television Studies, 53. 
21. Jason Mittell, "Forensic Fandom and the Drillable Text." Spreadablemedia.org, https:// spreadablemedia.org/essays/mittell/ <accessed on October 12, 2020>

22. Mittell, "Forensic Fandom and the Drillable Text".

23. For a synthetic presentation of TV studies and methodology, see Gray and Lotz, Television Studies, 28-32.

24. Gray and Lotz, Television Studies, 54 .

25. This rejection of close reading also exists in literary studies, see for instance Rabinowitz, who criticizes what he considers as the dogma of close reading in literature classes. For him, close reading "narrows perspectives" and runs the risk of discouraging students from certain kinds of research; Rabinowitz, Peter J., "Against Close Reading," in Pedagogy is Politics. Literary Theory and Critical Teaching, ed. Maria-Regina Kecht (Urbana and Chicago: University of Illinois Press, 1992), 237-38.

26. On the role of memory in our reception of TV series, see Jason Mittell, Complex TV: the Poetics of Contemporary Television Storytelling (New York: NYU Press, 2015), 164-205.

27. In the past few years, series have become shorter: seasons of cable or VOD shows tend to be 8 to 12-episodes long, unlike the 22-24-episode seasons which used to be the norm on Networks. Unsurprisingly, these shorter series, including miniseries (such as The Night Of) or anthologies (in which every season focuses a different story, such as American Horror Story or True Detective) lend themselves more easily to close analysis.

28. "[U]n écart ou une résistance par rapport à l'ensemble du tableau [...]. Très différent du regard lancé de loin, celui qui est posé de près, celui qui, selon Klee, 'broute' la surface, fait affleurer comme le sentiment d'une intimité, qu'il s'agisse de celle du tableau, du peintre ou de l'acte même de la peinture." Daniel Arasse, Le Détail (Paris: Champs Flammarion, 1992), 6-7. My translation.

29. See for instance Jean-Pierre Esquenazi, "Pouvoir des séries télévisées." Communications 32, no. 1, (2013), accessed February 07, 2020, https://journals.openedition.org/communication/4931 $<$ accessed on October 12, 2020>

30. See Frank Kelleter, ed., Media of Serial Narrative (Columbus: Ohio State UP, 2017); Alberto N. Garcia, ed., Emotions in Contemporary TV Series (Basingstoke: Palgrave Macmillan, 2016); and Jennifer Harding and Deirdre Pribram, eds. Emotions: A Cultural Studies Reader (London: Routledge, 2009).

31. Sudeep Dasgupta, "Sensing the Opaque. Seriality and the Aesthetics of Televisual Form," in Media of Serial Narrative, ed. Frank Kelleter (Columbus: Ohio State UP, 2017), 185.

32. Dasgupta, "Sensing the Opaque," 184.

33. Tom Gunning, "The Cinema of Attraction[s]: Early Film, Its Spectator and the Avant-Garde," Wide Angle 8, no. 3-4, (1986), 63-70.

34. Thomas Elsaesser, "The New Film History as Media Archaeology," Cinémas 14, no. 2-3 (Printemps 2004): 75-117.

35. James Walters and Tom Brown, eds., Film Moments: Criticism, History, Theory (London: BFI/ Palgrave Macmillan, 2010), xii.

36. Mittell, Complex TV, 7.

37. See for instance Éric Vérat, Génériques! Les séries américaines décryptées (Paris: Les Moutons Électriques, 2012); Valentina Re, "From Saul Bass to Participatory Culture: Opening Title Sequences in Contemporary Television Series," NECSUS, (Spring 2016). https://necsus-ejms.org/ saul-bass-participatory-culture-opening-title-sequences-contemporary-tv-series/ <accessed on October 12, 2020>

38. Some soap operas have gone on for decades, while many shows have been cancelled for bad ratings and have not been able to provide any deliberate closure.

39. See Vladimir Lifschutz, Vladimir, This is the end. Finir une série télé (Tours: PUFR, 2018). 
40. Rob Coley, "The Case of the Speculative Detective: Aesthetic Truths and the Television 'Crime Board'," NECSUS \#True, (Spring 2017). https://necsus-ejms.org/the-case-of-the-speculativedetective-aesthetic-truths-and-the-television-crime-board/. <accessed on October 12, 2020>

41. Anne Ganzert, "Serial Pinboarding” PhD diss., (University of Konstanz, 2017).

42. See Dasgupta, "Sensing the Opaque" for a close analysis of the passage in S02E07 in which characters react to a Rothko painting.

43. See Jake Nevins, "Aesthetic Excellence: How Cinematography Transformed TV," The Guardian, March 1, 2018. https://www.theguardian.com/tv-and-radio/2018/mar/01/tv-that-doesnt-looklike-tv-how-cinematography-relit-the-small-screen?CMP=Share_iOSApp_Other for the new essential role of cinematographers in TV series. <accessed on October 12, 2020>

44. Jeremy Butler, Television Style (New York and London: Routledge, 2010), 26. He quotes Tania Modleski, “The Search for Tomorrow and Today's Soap Opera; Notes on a Feminine Narrative Form", Film Quarterly 33, n¹, (fall 1979): 12-21.

45. See for instance Neil Miller, "The 140 Most Beautiful Shots of Game of Thrones." Film School Rejects (July 10, 2017). https://filmschoolrejects.com/140-beautiful-shots-game-of-thrones/. $<$ accessed on October 12, 2020>

46. S06E09, broadcast originally on HBO on June 19, 2016.

47. Jeremy Butler, Television Style, 108.

48. Sarah Hughes, "The Battle of the Bastards: Game of Thrones Serves Up TV's Finest Hour," The Guardian, September 19, 2016. https://www.theguardian.com/tv-and-radio/shortcuts/2016/sep/ 19/battle-of-the-bastards-game-of-thrones-episode-record-seven-emmys. <accessed on October 12, 2020>

49. See for instance "Three Brilliant Moments from 'The Battle of the Bastards"', Cinefix, July 6, 2016. https://www.youtube.com/watch? v=F8hExR0NXGI\&list=LLaYpLnwU7uqLYRcgGzrqxRw\&index=931 <accessed on October 12, 2020> 50. See for instance Timothy Bertrand, “'Battle of the Bastards' Yields Most Disturbingly Realistic Battle Sequence Since Saving Private Ryan", Social News Daily June 20, 2016. https:// socialnewsdaily.com/63718/battle-of-the-bastards-yields-most-disturbingly-realistic-battlesequence-since-saving-private-ryan/ <accessed on October 12, 2020>

51. Jason Mittell, "Forensic Fandom and the Drillable Text."

52. We could separate them into different categories: institutional paratexts for instance, which generally take the forms of the "Previously on" sequences (selections of relevant passages from the previous episode(s) to allow viewers to watch the next installment even if they have not necessarily seen the previous one. With VOD, replay, streaming or illegal downloading, it has become increasingly rare to rely on the actual broadcasting schedules, and yet the phenomenon remains strong, especially for popular shows such as Game of Thrones); trailers, posters, promotional short features, are also a way of lending, a priori, some specific weight to special moments in the upcoming season, and brief shots from the Battle of the Bastards featured in "Season 6 Event Promo (HBO)" https://www.youtube.com/watch?v=Gfmt5y8jfeQ. <accessed on October 12, 2020>. These promotional videos prior to the broadcasting of the first episodes could not reveal much, since the uncertainty over Jon Snow's death was the cliffhanger that ended the previous season. Other promotional trailers sometimes offer exclusively original material, such as the poetic trailer for the finale of Breaking Bad in which viewers discovered time-lapses? of locations associated with the series while Bryan Cranston's deep voice-over spoke the lines of Percy Bysshe Shelley's poem "Ozymandias." The foreboding tone of vanity and downfall conveyed there prepared us for the long-expected demise of Walter White.

53. "Game of Thrones Season 6: Anatomy of A Scene: The Battle of Winterfell (HBO)." YouTube, June 19, 2016. https://www.youtube.com/watch?v=B93k4uhpf7g. <accessed on October 12, 2020>

54. Showrunner David Benioff notably insists: “That cavalry wall galloping towards him [...] part of the reason it's such a great shot is that it's all real, that's 40 horses charging full speed at Kit 
Harrington." The latter expresses his regret that the "reality" of the scene might be lost to viewers: "We're a bit annoyed because everyone's gonna think it was CGI, but it wasn't."

55. Echoed later on by the broader institutional recognition at the Emmy Awards Ceremony, since the episode received 7 Emmys, including best writing and best directing.

56. These reaction videos often address the most dramatic, shocking sequences of the show such as the "Red Wedding", during which major characters were slaughtered (S03E09). See also Sean TankTop, June 21, 2016, "Reactions at Burlington Bar, Battle of the Bastards Pt 2." https:// www.youtube.com/watch?v=cK3P3E05xac. <accessed on October 12, 2020>

57. Omid G, "Game of Thrones: Battle of the Bastards (Star Wars Edition)," June 25, 2016, accessed December 20, 2020, https://www.youtube.com/watch?v=XIEviEQjk8o\&t=195s. <accessed on October 12, 2020>

58. KnightSquire, “What Jon Shouda Done," July 20, 2016. https://www.youtube.com/watch? $\mathrm{v}=\mathrm{m0QPD} 908 \mathrm{~K} 8 \mathrm{w} .<$ accessed on October 12, 2020>

59. Grable424, “(GOT) Battle of the Bastards // Kings," June 23, 2016. https://www.youtube.com/ watch?v=igS5-zUdm0k. <accessed on October 12, 2020>

60. On the link between GIFs and early cinema of attractions, see notably Eric Stewart, "Reanimating GIF's," Otherzine 28, Spring 2015. http://www.othercinema.com/otherzine/ reanimating-gifs/. <accessed on October 12, 2020>

61. "3 Brilliant Moments from the Battle of the Bastards," July 6, 2016. https:// www.youtube.com/watch?v=F8hExR0NXGI. <accessed on October 12, 2020> For other video analyses, see for instance: New Rockstars, "Game of Thrones 6x09 Battle of the Bastards ANALYSIS - Season 6 Episode 9 - Winterfell Crypts!” June 26, 2016. https://www.youtube.com/ watch?v=7PpapUvfeao <accessed on October 12, 2020> or scholagladiatoria, "Game of Thrones: Battle of the Bastards Review," June 21, 2016. https://www.youtube.com/watch?v=avtHpJyYYkQ. $<$ accessed on October 12, 2020>

62. Sarah Hughes, "The Battle of the Bastards: Game of Thrones Serves Up TV's Finest Hour," The Guardian, September 19, 2016. https://www.theguardian.com/tv-and-radio/shortcuts/2016/sep/ 19/battle-of-the-bastards-game-of-thrones-episode-record-seven-emmys. <accessed on October $12,2020>$

63. Myles McNutt, “Thrones Stages an Epic Battle, but to What End?" the AVclub, June 19, 2016. https://tv.avclub.com/thrones-stages-an-epic-battle-but-to-what-end-expert-1798188762. $<$ accessed on October 12, 2020>

\section{ABSTRACTS}

In the past decades, the audiovisual aesthetics of TV series have been particularly impacted by technical, media and industrial changes. The competition between networks and cable, then VOD (Video On Demand) platforms, the new spectatorial control over the rhythm and modes of reception, as well as the shift to digital technologies have all led many series to develop increasingly complex modes of audiovisual expression and to gain new cultural legitimacy. Meanwhile, the aesthetics of television series have likewise undergone a revival. This article synthesizes the recent debates around the visual changes in TV series and offers a reflection on the methods that can be applied to the aesthetic analysis of television serials. There cannot be a universal mode of handling an entire series, notably because of the problem of long duration. These long works are difficult to handle, both materially (we need to juggle between 
several DVDs, or heavy digital files) and mentally (how can our brains retain the details of such long, protean works?). Just as scientific inquiry requires the choice of adequate tools (scalpel, knife or saw; microscope or telescope), scholars who study television series have to select the right optical frame: should we strive for a comprehensive vision of such massive works, and is such a thing even possible? Or should we rely on fragments, and if so, which ones? Using a passage from Game of Thrones, the "Battle of the Bastards" as a case study, this paper will shed light on how the series showcases such moments of "attractions" as emblematic of its aesthetic system, and on the way in which such a passage can emerge as a memorable moment in the reception process.

\section{INDEX}

Keywords: TV series, TV studies, TV aesthetics, immersion, reception

\section{AUTHOR}

\section{ARIANE HUDELET}

Ariane Hudelet is Professor of Visual Cultures at Université de Paris, where she teaches in the English department. She is the author of The Wire, les règles du jeu (Presses Universitaires de France, 2016) co-editor of La Sérialité à l'écran (PUFR, 2020) and Exploring Seriality on Screen (Routledge, 2021). She also co-directs the TV/Series journal (https://journals.openedition.org/ tvseries/). Before focusing on TV series, she worked on adaptation and intermediality (Screening Texts. Critical Perspectives on Film Adaptation, with Shannon Wells Lassagne, eds., McFarland, 2013; The Cinematic Jane Austen, with David Monaghan and John Wiltshire, McFarland, 2009).

Université de Paris, LARCA, CNRS, F-75013 Paris, France

ariane.hudelet@u-paris.fr 